Conclusion: There is an association between use of certain types of antibiotics and the diagnosis of AS, but no dose-response gradient. These data do not support a causal effect of cumulative antibiotic use on the development of AS. More research is needed on the impact of microbiome disturbance on the risk of developing AS.

Acknowledgments: Partial support received from the Oxford NIHR Biomedical Research Centre (BRC)

Disclosure of Interests: Ana Pascual-Dapena: None declared, Albert PratsUribe: None declared, Daniel Prieto-Alhambra Grant/research support from: Professor Prieto-Alhambra has received research Grants from AMGEN, UCB Biopharma and Les Laboratoires Servier, Consultant of: DPA's department has received fees for consultancy services from UCB Biopharma, Speakers bureau: DPA's department has received fees for speaker and advisory board membership services from Amgen

DOI: 10.1136/annrheumdis-2020-eular.4405

\section{OP0068 INCIDENCE AND PREVALENCE OF RHEUMATOID ARTHRITIS IN DENMARK: A NATIONWIDE POPULATION-BASED STUDY INVESTIGATING THE EFFECT OF FOUR DIFFERENT CASE DEFINITIONS}

B. G. Soussi ${ }^{1}$, R. L. Cordtz ${ }^{1}$, S. Kristensen ${ }^{1}$, C. S. Bork ${ }^{2}$, J. Christensen ${ }^{3}$, E. B. Schmidt' ${ }^{2}$, D. Prieto-Alhambra ${ }^{4}$, L. Dreyer ${ }^{1} .{ }^{1}$ Aalborg University Hospital, Department of Rheumatology, Aalborg, Denmark; ${ }^{2}$ Aalborg University Hospital, Department of Cardiology, Aalborg, Denmark; ${ }^{3}$ Aalborg University Hospital, Department of Nephrology, Aalborg, Denmark; ${ }^{4}$ University of Oxford, CSMNDORMS, Oxford, United Kingdom

Background: The incidence rate (IR) and point prevalence (PP) of rheumatoid arthritis (RA) in Denmark is largely unknown. Two challenges in estimating the "true" IR and PP using nationwide registry data are the choice of the RA case definition, and the denominator used, i.e. the exact amount of person years (PY) or census count data.

Objectives: To investigate the incidence and prevalence of RA in the adult Danish population using four different case definitions and two different denominator strategies.

Methods: Nationwide register-based cohort study. Patients with RA between 1996 and the end of 2016 were identified using the Danish National Patient Registry (DNPR) and information on DMARD prescriptions were obtained through linkage with the Danish National Prescription Registry. Age and sex standardised incidence and prevalence of RA were calculated in different ways: we estimated the IR (denominator $=$ actual recorded number of PY in each year using migration and vital data) and the incidence proportion (IP) (denominator = census count data); and the PP (\%) of RA was calculated for years 2000, 2009, 2011 and 2016. The four case definitions were: Model A, a first time RA diagnosis (ICD-10: M05-06) in DNPR and a redeemed prescription of a conventional DMARD in the following year ${ }^{1}$; Model $\mathrm{B}$, an RA diagnosis recorded twice in DNPR within 90 days with both records originating from a department of rheumatology or general internal medicine ${ }^{2}$; Model $\mathrm{C}$, any RA diagnosis recorded in DNPR with a DMARD prescription redeemed in the year before or after the diagnosis; Model D, similar to Model A but with the additional requirement that cases had no registered ICD code for inflammatory diseases prior to the RA diagnosis ${ }^{1}$.

Results: The overall IR of RA from 1996 to 2016 based on model A was 35.2 (95\% Cl 34.8 to 35.6$)$ per 100,000 PY while the IP was 34.7 (95\% $\mathrm{Cl} 34.3$ to 35.1 ) per 100,000 individuals. The age standardised IR was higher for women than for men (Figure 1), and this was observed across all age groups. The IR peaked at age 70 to 74 in both men and women. Regardless of which case definition was used, the temporal trend showed a peak in IR in 2010 followed by a plateau (Figure 2). The overall PP estimate for all four models increased from 2000 to 2016 , data shown for Model A in Table 1.

Table 1. Point prevalence (PP) of rheumatoid arthritis in years 2000 , 2009, 2011 and 2016 based on Model A

\begin{tabular}{|c|c|c|c|c|}
\hline & $\begin{array}{c}2000 \\
N=5906 \\
70.3 \% \text { women }\end{array}$ & $\begin{array}{c}2009 \\
N=15037 \\
70.9 \% \text { women }\end{array}$ & $\begin{array}{c}2011 \\
N=17363 \\
71.0 \% \text { women }\end{array}$ & $\begin{array}{c}2016 \\
N=22991 \\
70.3 \% \text { women }\end{array}$ \\
\hline & PP (\%) $(95 \% \mathrm{Cl})$ & PP (\%) $(95 \% \mathrm{Cl})$ & PP (\%) $(95 \% \mathrm{Cl})$ & PP (\%) $(95 \% \mathrm{Cl})$ \\
\hline All & 0.16( & 0.37 & 0.41 & 0.52( \\
\hline Women & $0.21(0.20$ to 0.22$)$ & 0.50 (0.49 to 0.51$)$ & 0.57 (0.56 to 0.58$)$ & 0.71 (0.70 to 0.72$)$ \\
\hline Men & $0.10(0.10$ to 0.11$)$ & 0.23 (0.22 to 0.23$)$ & $0.25(0.25$ to 0.26$)$ & $0.32(0.31$ to 0.33$)$ \\
\hline
\end{tabular}
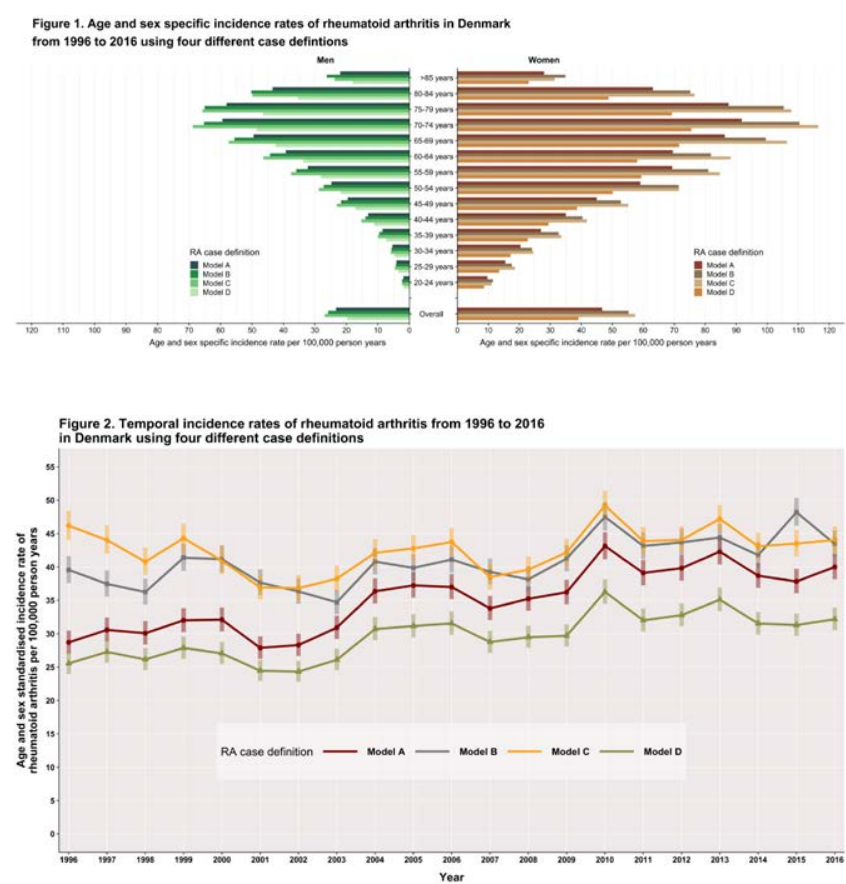

Conclusion: A peak in the IR of RA was observed in 2010, regardless of which case definition was used. We believe this was due to introduction of the new EULAR/ACR diagnostic criteria at that time. IP estimates were systematically lower than IRs calculated using exact migration and vital data as denominator. The PP increased over time regardless of which case definition we used. We conclude that the choice of RA case definition had a larger influence than the choice of denominator.

\section{References:}

[1] inauskas A et al. Positive predictive value of first-time rheumatoid arthritis diagnoses and their serological subtypes in the Danish National Patient Registry. Clin Epidemiol. 2018;10:1709-1720.

[2] Ibfelt $\mathrm{E}$ et al. Validity and completeness of rheumatoid arthritis diagnoses in the nationwide DANBIO clinical register and the Danish National Patient Registry. Clin Epidemiol. 2017:627-632.

Acknowledgments: The study is funded by the Danish Rheumatism Association. Disclosure of Interests: Bolette Gylden Soussi: None declared, René Lindholm Cordtz: None declared, Salome Kristensen: None declared, Christian Sørensen Bork: None declared, Jeppe Christensen: None declared, Erik Berg Schmidt: None declared, Daniel Prieto-Alhambra Grant/research support from: Professor Prieto-Alhambra has received research Grants from AMGEN, UCB Biopharma and Les Laboratoires Servier, Consultant of: DPA's department has received fees for consultancy services from UCB Biopharma, Speakers bureau: DPA's department has received fees for speaker and advisory board membership services from Amgen, Lene Dreyer: None declared

DOI: 10.1136/annrheumdis-2020-eular.891

\section{OP0069 \\ FACTORS ASSOCIATED WITH THE RISK OF SEPSIS IN PATIENTS WITH IMMUNE-MEDIATED INFLAMMATORY DISEASES TREATED WITH ANTI-TUMOR NECROSIS FACTOR-ALPHA: A NATIONWIDE, POPULATION- BASED COHORT STUDY}

B. C. Hsu ${ }^{1}$, H. H. Chen ${ }^{2,3}$, C. H. Lin ${ }^{2}$, Y. M. Chen ${ }^{2,3}$, K. L. Lai ${ }^{3}$, D. Y. Chen ${ }^{4}$, W. N. Huang ${ }^{3}$, Y. H. Chen ${ }^{3}{ }^{1}$ Taichung Veterans General Hospital Puli Branch, Internal Medicine, Nantou, Taiwan, Republic of China; ${ }^{2}$ Taichung Veterans General Hospital, Medical Research, Taichung, Taiwan, Republic of China; ${ }^{3}$ Taichung Veterans General Hospital, Internal Medicine, Taichung, Taiwan, Republic of China; ${ }^{4}$ China Medical University, College of Medicine, Taichung, Taiwan, Republic of China

Background: Anti-TNF-a agents have been proven to be effective for patients with immune-medicated inflammatory diseases (IMIDs) including rheumatoid arthritis (RA), ankylosing spondylitis (AS), psoriasis (PsO), psoriatic arthritis (PsA), Crohn's disease (CD) and ulcerative colitis (UC). Prior studies have shown an increased risk of infection in IMID patients treated with anti-TNF-a but limited studies investigated factors associated with the development of sepsis in patients with IMIDs. 